\title{
Erratum: Improving the Prediction of Benign or Malignant Breast Masses Using a Combination of Image Biomarkers and Clinical Parameters
}

\author{
Frontiers Production Office*
}

Frontiers Media SA, Lausanne, Switzerland

Keywords: mammography, image feature, deep learning, clinical prediction, radiomics

\section{An Erratum on}

Improving the Prediction of Benign or Malignant Breast Masses Using a Combination of Image Biomarkers and Clinical Parameters

By Cui Y, Li Y, Xing D, Bai T, Dong J and Zhu J (2021). Front. Oncol. 11:629321. doi: 10.3389/fonc.2021.629321

\section{OPEN ACCESS}

Approved by:

Frontiers Editorial Office,

Frontiers Media SA,

Switzerland

*Correspondence:

Frontiers Production Office production.office@frontiersin.org

Specialty section:

This article was submitted to

Cancer Imaging and Image-directed Interventions,

a section of the journal

Frontiers in Oncology

Received: 12 April 2021 Accepted: 12 April 2021

Published: 29 April 2021

Citation:

Frontiers Production Office (2021) Erratum: Improving the Prediction of Benign or Malignant Breast

Masses Using a Combination of Image Biomarkers and

Clinical Parameters.

Front. Oncol. 11:694094

doi: 10.3389/fonc.2021.694094
Due to a production error, in the original article, references (1-15) were incorrectly ordered. The correct order and references are provided below. The publisher apologizes for this error and state that this does not change the scientific conclusions of the article in any way. The original article has been updated.

\section{REFERENCES}

1. Raza S, Goldkamp AL, Chikarmane SA, Birdwell RL. US of Breast Masses Categorized as BI-RADS 3, 4, and 5: Pictorial Review of Factors Influencing Clinical Management. Radiographics (2010) 30:1199. doi: 10.1148/rg.305095144

2. Simonyan K, Zisserman A. Very Deep Convolutional Networks for Large-Scaleimage Recognition. In: Cvpr. Piscataway, NJ: IEEE (2014)

3. Russakovsky O, Deng J, Su H, Krause J, Satheesh S, Ma S, et al. Imagenet Large Scale Visual Recognition Challenge. Int J Comput Vision (2015) 115:211-52. doi: 10.1007/s11263-015-0816-y

4. Szegedy C, Vanhoucke V, Ioffe S, Shlens J, Wojna Z. Rethinking the Inception Architecture for Computer Vision. In: Cvpr. Las Vegas, NV (2016). p. 2818-26. doi: 10.1109/CVPR.2016.308

5. Yuan Y, Chao M, Lo YC. Automatic Skin Lesion Segmentation Using Deep Fully Convolutional Networks With Jaccard Distance. IEEE Trans Med Imaging (2017) 36:1876-86. doi: 10.1109/TMI.2017.2695227

6. Gal Y, Ghahramani Z. Dropout as a Bayesian Approximation: Representing Model Uncertainty in Deep Learning. In: Icml. New York, NY (2016). p. 1050-9.

7. Li Z, Mao Y, Huang W, Li H, Zhu J, Li W, et al. Texture-Based Classificationof Different Single Liver Lesion Based on SPAIR T2w MRI Images. BMC MedImaging (2017) 17:1-9. doi: 10.1186/s12880-017-0212-x

8. Peng H, Long F, Ding C. Feature Selection Based on Mutual Informationcriteria of Max-Dependency, Max-Relevance, and Min-Redundancy. IEEE Trans Pattern Anal (2005) 27:1226-38. doi: 10.1109/TPAMI.2005.159

9. Zhang D. Support Vector Machine. In: Fundamentals of Image Data Mining. Springer (2019). p. 179-205. doi: 10.1007/ 978-3-030-17989-2_8

10. Ragab DA, Sharkas M, Marshall S, Ren J. Breast Cancer Detection Using Deep Convolutional Neural Networks and Support Vector Machines. PeerJ (2019) 7:e6201. doi: 10.7717/peerj.6201

11. Yassin NIR, Omran S, El Houby EMF, Allam H. Machine Learning Techniques for Breast Cancer Computer Aided Diagnosis Using Different Image Modalities: A Systematic Review. Comput Meth Prog Bio (2018) 156:25-45. doi: 10.1016/ j.cmpb.2017.12.012 
12. DeLong ER, DeLongb DM, Clarke-Pearson DL. Comparing the Areas Under Two or More Correlated Receiver Operating Characteristic Curves: Anonparametric Approach. Biometrics (1988) 44:837-45. doi: 10.2307/ 2531595

13. Moura DC, López MAG. An Evaluation of Image Descriptors Combined With Clinical Data for Breast Cancer Diagnosis. Int J Comput Ass Rad (2013) 8:56174. doi: 10.1007/s11548-013-0838-2

14. Tsochatzidis L, Costaridou L, Pratikakis I. Deep Learning for Breast Cancer Diagnosis From Mammograms-a Comparative Study. J Imaging (2019) 5:37. doi: $10.3390 /$ jimaging 5030037
15. Kooi T, Litjens G, Van Ginneken B, Gubern-Mérida A, Sánchez CI, Mann R, et al. Large Scale Deep Learning for Computer Aided Detection of Mammographic Lesions. Med Image Anal (2017) 35:303-12. doi: 10.1016/j.media.2016.07.007

Copyright (c) 2021 Frontiers Production Office. This is an open-access article distributed under the terms of the Creative Commons Attribution License (CC BY). The use, distribution or reproduction in other forums is permitted, provided the original author(s) and the copyright owner(s) are credited and that the original publication in this journal is cited, in accordance with accepted academic practice. No use, distribution or reproduction is permitted which does not comply with these terms. 